\section{APPLICATIONS OF D.D.T.}

$\mathrm{T}$

YPHUS can upset the plans and frustrate the might of the most powerfully armed forces. During the War of 1914-18 it killed some 10,000 people in six months in Serbia ; after the Russian Revolution it killed some three million Russians. It has been recorded that during the siege of Granada and in the Thirty Years' War and the campaigns of Napoleon, it killed more people than the military weapons then in use. A disease which frequently attacks starved and disorganized populations and flourishes in times of national disaster, it broke out in Spain in 1908 and again in 1941 , and it is a constant problem in the South American States and elsewhere. It has to be watched constantly, and the pages of the Tropical Diseases Bulletin, the Bulletin of War Medicine, the Boletin de la Oficina Sanitaria Panamericana and other medical journals record the work that is being done on all its aspects.

Epidemic typhus is caused by Rickettsia prowazeki transmitted rapidly from man to man by head and body lice. It should be distinguished carefully from endemic typhus, which is transmitted from rats to man by the rat flea. The old epidemiological rule "no lice, no typhus", quoted by the Lancet (11 5, July 22, 1944) still applies to epidemic typhus, and the best method of control is to attack this link in the epidemiological chain. Until recently, the lice have been attacked by heat and fumigation, and the organization and conduct of delousing stations has been no easy task, especially when large populations have had to be deloused. These methods, moreover, do not keep a population free from re-infestation with lice, which quickly occurs. Until comparat vely recently, no insecticide was known which would keep a person free from lice for longer than two days or so. Early in this War, work was undertaken to find new insecticides. A general review of the discovery and properties of D.D.T. was contributed to Nature of September 16, p. 352, by Prof. J. W. Munro. The story, so far as it concerns typhus, is briefly told in the Lancet (115, July 22, 1944) and the British Medical Journal (217, August 22, 1944).

Early in the War, British scientific men produced an insecticide called AL 63 , which protected persons from lice for five-six days when it was dusted on to their underwear. Organic thiocyanates sprayed on to underwear protected the wearer for a month and could also be used on a belt so devised that it attracted the lice and then killed them; but these thiocyanates caused smarting when those who used them began to sweat. When the United States entered the War, teams of workers were put on this problem, and a dust called MYL was produced (Soap and Sanitary Chemicals, 105, November 1942), which was recommended by the U.S. Bureau of Entomology and Plant Quarantine. Russian workers had, in the meantime, developed two synthetic compounds, a powder containing diphenylamine, which was successfully used on civilians in Moscow (Fedder, M. L., Gigiena $i$ Zdorov'e, No. 10, 12; 1942; quoted by the Lancet, loc. cit.) and bis-ethyl-xanthogen, with which garments worn by Russian soldiers in Bessarabia were impregnated (Gorkina, A. N., Med. Parasitol., Moscow, 11, 90 ; 1942; quoted by the Lancet, loc. cit.). Then came the discovery that the synthetic compound 2,2-bis (parachlorphenyl) $1,1,1,-$ trichlorethane), which has been called D.D.T., from the generic name dichlor-diphenyl-trichlorethane, has insecticidal properties of considerable promise. D.D.T. was first synthesized by the German chemist $O$. Ziedler in 1874 (Deutch. Chem. Gesell., 7, 1180 ; 1874). Its insecticidal properties were apparently first made known by Paul Müller in Switzerland, when he reported his work with it on moths, flies and plant lice. In 1940 the Swiss firm of Geigy and Co., of Basle, patented it. Preparations of it are available under the name "Gesarol", either as a spray containing 5 per cent of D.D.T. with a wetting agent, or a dust containing 3 per cent of D.D.T.; another dust, called "Neocid", containing 5 per cent D.D.T. was produced for treating human lice.

Methods of manufacture were quickly improved and the toxicity of D.D.T. to a large number of insect pests, as well as to human lice, has been tested. An account of this work has been given by $P$. N. Annand and his co-workers (J. Econ. Entom., 125, 37, February 1944), and the earlier work done with D.D.T. in Switzerland and Germany is there noted.

Annand concludes that D.D.T. is "one of the more promising synthetic organics" for the control of insects-a sober statement which should be borne in mind in these days when publicity is apt to exalt new discoveries far beyond the claims made for them by scientific workers. A reaction of some insects suggests, Annand says, that it acts as a nerve poison. It is distinctly toxic when it is dissolved in solvents such as oil, which can penetrate the skin, or when it is ingested; and more work is needed on its toxicity to man and animals. Appropriate precautions should therefore be taken by personnel who employ it as a dust likely to be inhaled or swallowed or in oily solvents. But in the concentrations in which it has been used for the control of human lice, it is apparently safe if reasonable precautions are taken : in these concentrations it does not appear to irritate the human skin.

D.D.T. is a crystalline solid, practically colourless and practically odourless, which results from the interaction of anhydrous ch!oral and chlorobenzene in the presence of concentrated sulphuric acid. It is insoluble in water, but soluble in most organic solvents. It is 'rather stable' and its volatility is low, so that loss of it from spray deposits is too slow to decrease its activity appreciably.

The tests of its action on human body and head lice and also on the human crab louse recorded by P. N. Annand (loc. cit.) indicate that it is highly effective and that its action lasts longer than that of any other louse treatment. It is better than MYL. It can be used as a powder diluted with kaolin or pyrophyllite, and such powders will protect grossly infested persons against lice for two to three weeks and will give effective control of lice for longer periods. It is equally effective against head or crab lice. The powder can be blown up the sleeves or down the necks of dressed persons, and this was done in controlling the outbreak of typhus earlier this year at Naples. The method is quick and has enabled the Naples authorities to treat a maximum number of 73,000 persons in a single day-a feat which could not be equalled by any other method. Another way of using it is to impregnate undergarments with it by dipping them in a solution containing D.D.T. in volatile solvents or in aqueous emulsions containing it. Both methods are good for either cotton or woollen garments. It is claimed that such garments will protect their wearers for three to five weeks without washing. Garments washed once a week protect for two to three weeks, or with stronger solutions for five to six weekly washes. Even stronger solutions will 
protect for nine weekly washings. For the troops, a solution rendering garments protective for six to eight weekly washings has been recommended, and arrangements for large-scale treatment of such garments have been made.

Apart from its value for the control of typhus, D.D.T. may prove valuable for the control of a wide variety of insect pests. Annand and his co-workers (loc. cit.) report the results of their tests of its action on the bedbug, the house- and stable-fly, ticks and fieas of dogs, goat lice, "German" cockroaches (Blattella germanica), ants and termites, larvæ of the house-fly and numerous plant pests. For the control of the larvæ of malaria-carrying mosquitoes it is being tried as an emulsion sprayed over waters containing them, and the method of spraying it from the air is also being tried in an attempt to kill mosquitoes infected with malaria in areas in which troops have to operate. For the control of some species of cockroach it certainly seems to be effective. Recently an appeal reached the writer from a Manchester hospital for some means of exterminating a pest of 'steamflies' (Blattella germanica) on the hospital premises; Dr. H. Hurst sent a supply of a preparation containing D.D.T. and pyrethrum, with very good results. J. M. Ginsburg records ( $J$. Econ. Entom., loc. cit.) the results of his experiments on the action of D.D.T. on this species of cockroach, which is a growing and serious pest in various parts of North and South America. Ginsburg found that the minimal concentration of D.D.T. required to kill 100 per cent of these cockroaches in jars in 48 hours was 7 per cent, while 33 per cent of sodium fluoride was required to kill 100 per cent of the cockroaches under the same conditions. In the same time a dust containing 33 per cent of derris killed only 30 per cent of them, while a dust containing 33 per cent of pyrethrum killed 90 per cent. If D.D.T. is as toxic as this to Blatella germanica, the work now being done on its action on locusts should be interesting.

Much of the work on D.D.T. is summarized by V. H. Chambers, G. L. Hey and N. K. Smitt, of the Murphy Chemical Company, Wheathampstead, in a reprint of an article in the Market Grower 62 Doughty Street, W.C.1 - the date of the issue of this journal containing this article is not given). These authors refer to the work with D.D.T. done in Switzerland by R. Wiesmann (Schueitz. Z. Obst.-u. Weinbau, 51, $155,206,245$ and $329 ; 1942$ ) on its effect on bees and fruit and vine pests and (Anz. Schadlingskunde, Berlin, 19, 5; 1943) on flies in cowsheds. These authors also describe their own work with D.D.T. in the form of the Murphy Chemical Company's proprietary spray called 'DeDeTane' and with this Company's other preparations of D.D.T. Encouraging results were obtained against caterpillars of the tomato moth and against the grain weevil and the apple blossom weevil. 'DeDeTane' was, however, not so effective as nicotine against the apple sawfly, and it failed to control the plum leaf-curling aphis. Its possibilities as a means of controlling other insect pests are discussed, and the American work is summarized. D.D.T. may, according to this article, partly replace pyrethrum in the aerosol 'bombs' widely used by the United States Army for the disinfestation of tents, aeroplanes, buildings, etc. (But Mr. Lyttelton has announced in Parliament that the entire output of D.D.T. is being taken for military use and that, apart from a small quantity released for use in air-raid shelters, none can be released for civilian use (The Lancet, 485, Oct. 7, 1944).) In a reprint from Fruit (W. Seabrook and Sons, Chelmsford-the date of the issue of this journal containing this article is not given) it is claimed that in a field trial of 'DeDeTane' against the apple blossom weevil, a "very large reduction of infestation was secured". It is concluded, however, that much more work is required before the e.tcacy of D.D.T. against this weevil can be finally assessed.

It is clear that D.D.T. will have many uses other than the control of the lice which transmit typhus. Field tests should be made on its action on such insect pests of domesticated animals as the blowfly and the lice of mammals and birds. It might even prove useful against human scabies and the scab mites of animals. But we must not expect too much of it. Local factors in the environment will always affect the action of even the best insecticide. It is one thing, for example, to kill 100 per cent of houseflies or mosquito larvæ with D.D.T. or any other substance in the laboratory, and quite another to kill these quickly on a large scale in a tropical area where they are causing the deaths or illnesses of large numbers of human beings; or to do the same thing among populations whose normal habits, or disorganization during disaster, stultify the best of sanitary plans; or to apply such a remedy to large herds and flocks of domesticated animals or to extensive crops in the spacious areas of America or Australia. All remedies of this nature are subject to this kind of limitation. We are fortunate, indeed, in having, while the War lasts, opportunities for the control of both the experimental man or animal and of their environment which should enable us to investigate these aspects of the problem more thoroughly than we could investigate them in times of peace. In this respect, our partial and, we hope, temporary, loss of freedom is a help rather than a hindrance to progress.

G. Lapage.

\section{OBITUARIES}

\section{Mr. H. P. Marks}

Henry Percy Marks, a member of the scientific staff of the Medical Research Council at the National Institute for Medical Research, died on September 13 after a short illness. After serving in the Navy in the War of 1914-18, Marks joined the Medical Research Council as an attached worker at Hampstead in 1922, and was appointed a member of the staff in 1927. His work at Hampstead was mainly concerned with insulin and carbohydrate metabolism although, in collaboration with others at the Institute, he also carried out interesting work on the mechanism of action of calciferol. More recently, Marks had become interested in the influence of the pituitary gland on carbohydrate metabolism and had published a number of papers on this aspect of the subject. For the two years immediately preceding his death he had been assisting in research work of national importance in connexion with the War, and had undertaken the arduous duties involved with the enthusiasm of a man many years younger. His untimely death will be mourned by his many colleagues and friends at Hampstead and elsewhere.

Marks's most important work was concerned with the standardization of insulin and more recently with the standardization of potamine zinc insulin. $\mathrm{He}$ visited both Copenhagen and Toronto in this con- 